\title{
Micro-scale elemental distribution in the thallus of Flavoparmelia caperata transplanted to polluted site
}

\author{
R. M. Godinho - H. T. Wolterbeek - M. T. Pinheiro • \\ L. C. Alves · T. G. Verburg - M. C. Freitas
}

Received: 19 April 2009/Published online: 1 July 2009

(c) Akadémiai Kiadó, Budapest, Hungary 2009

\begin{abstract}
The elemental microdistributions of peripheral and central parts of the lichen Flavoparmelia caperata exposed to industrial pollution were analysed, in order to better understand the elements distribution patterns in relation to the lichen constitution, thereby increasing our knowledge on uptake and release mechanisms. Nuclear microscopy techniques were used to visualize elemental distributions in sample transepts and associate their concentrations to sample morphology. The distribution data of the elements studied suggests there is biological regulation of internal concentrations. Considering thallus parts, element-specific internal translocation should be taken into account as one more factor affecting lichen "memory length".
\end{abstract}

Keywords Flavoparmelia caperata - Micro-PIXE . STIM · Element microdistribution

\section{Introduction}

In the context of air pollution biomonitoring by lichens, it is crucial to understand the relations between the lichen and the pollutants in terms of lichen eco-physiology. The

R. M. Godinho $(\bowtie) \cdot$ M. T. Pinheiro - L. C. Alves .

M. C. Freitas

Technological and Nuclear Institute, E.N. 10, 2686-953

Sacavém, Portugal

e-mail: rveloso@itn.pt

\section{H. T. Wolterbeek · T. G. Verburg}

Department R3 (Radiation, Radionuclides \& Reactors), Section Radiation and Isotopes for Health (RIH), Faculty of Applied Sciences, Delft University of Technology, Mekelweg 15, 2629 JB Delft, The Netherlands patterned accumulation and zoning of metal concentrations in lichen thalli is an actual issue associated with the use of lichens as biomonitors. Element-specific partitioning between old and younger parts of foliose lichen thallus is reported and suggested as influencing the biomonitoring results [1-4]. It was also hypothesized that differences in the lichen thallus constitution (algae, fungi) may cause the different patterns of element distribution in peripheral and central lichen parts [3].

In the general dynamics of element uptake and release, specific components which affect total behaviour, or which are relevant in sampling, or in the handling of the lichen samples should be extensively studied. In this context the comparability of lichen sub-parts should be investigated in terms of particle entrapment, and uptake and release processes. Here, differences between pseudo-tissues (e.g. heterogeneities in internal distribution of myco- and photobionts) may result in differences in response. The internal spatial distribution of the elements is a reflection of the pathways of transport and influences the extraction potential and toxicity of the elements. Therefore insight in distribution patterns may help to understand the lichen rates of accumulation and release being related with lichen remembrance time [5-7].

Various methods have been used to study spatial distributions, such as sequential elution techniques [8], X-ray microanalysis [9] and microscopic histochemistry methods [10]. Proton microprobe techniques based on focused proton beams generated in particle accelerators permit the direct microanalysis of individual biological samples. It delivers images of the sample morphology and elemental distributions providing not only low detection limits, but also spatial information necessary to understand physiological and biochemical relationships [11]. Moreover, it allows the estimation of element accumulation without the 
risk of taking into account the metals present in dust on the lichen surfaces. However, so far, only few micro-PIXE studies have been carried out on lichens [12-15].

Most of these microdistribution studies highlight particle entrapment in interhyphal spaces and mineralised structures as the main cause of high metals contents in thalli with detoxifying mechanisms emphasizing the fungus toxicity protection role [16, 17]. However, these interpretations do not explain the relatively short time-scale changes in lichen mineral composition in a fast response to changes in ambient elemental availability [3, 18]. In addition to particle entrapment, lichens can acquire substances from the environment by extra- or intra-cellular uptake of ions in solution. The uptake of metals from solution by lichens has been studied in laboratory experiments but information on the participation of both symbiotic partners in the uptake and final localization of compounds is scarce [19].

The present work focuses on the elemental microdistributions of thin sections of peripheral and central parts of foliose lichen Flavoparmelia caperata after field exposure to industrial pollution, in order to better understand the elements distribution patterns in relation to the lichen constitution, thereby increasing our knowledge on uptake and release mechanisms. The foliose lichen Flavoparmelia caperata was chosen for this work because it is one of the most abundant species in Portugal and is often used as a biomonitor, including by our research group.

\section{Experimental}

Flavoparmelia caperata thalli, average diameter $3-4 \mathrm{~cm}$, were collected from pine trees located in a clean rural zone in the centre of Portugal $\left(39^{\circ} 30^{\prime} \mathrm{N}, 08^{\circ} 00^{\prime} \mathrm{W}\right)$, near Tomar, and transplanted to a polluted location, $180 \mathrm{~km}$ southwest of Tomar, near Sines' coal power station. Transplants were exposed inside a polyamide net $(61 \mu \mathrm{m}$ porosity), hanging protected from direct rain, during 4 months. Experimental details are described elsewhere [3, 20].

At the end of the exposure, the samples were rinsed three times with double distilled water for $5 \mathrm{~s}$, air dried for $24 \mathrm{~h}$ at room temperature, freeze dried by immersion in liquid nitrogen and kept frozen at $-50{ }^{\circ} \mathrm{C}$ until analysis. The lichen thalli were sectioned using a cryo microtome at $-65{ }^{\circ} \mathrm{C}$ with a glass knife. Sectioning was accomplished by immobilizing the sample in a drop of water and immediately freezing by immersion in liquid nitrogen (modified from [12]). Sections were generally 1-2 mm long (long samples allow better results), $0.5 \mathrm{~mm}$ wide and $15 \mu \mathrm{m}$ thick. Thinner samples $10-12 \mu \mathrm{m}$ break easily during manipulation and often burn during analysis.
Sections were mounted self-supported onto sticky carbon tabs, glued to an Al-holder, and classified from young (peripheral), the outermost 3-4 mm of the thallus, the lobes distinguishable by their colour and their lack of rhizinae, equivalent to an age of about 1 year, to older (central), more central part of the thallus [3]. The samples were examined at the proton microprobe set up of Instituto Tecnológico e Nuclear of Sacavém [21]. Shortly, a proton beam of $2 \mathrm{MeV}$ energy with a current of $100 \mathrm{pA}$ and of $3 \mu \mathrm{m}$ resolution was used to scan the sample areas of interest. Particle induced X-ray emission (PIXE), Rutherford backscattering spectrometry (RBS), and scanning transmission ion microscopy (STIM) were used simultaneously to obtain morphological and quantitative elemental distribution data. PIXE technique provides minor and trace elemental information. RBS enables the measurement of matrix composition, depth variations and sample stoichiometry. STIM provides measures of density variations, and high-resolution images $(<0.5 \mu \mathrm{m})$ of the sample morphology. The combination of PIXE and RBS data allows quantitative measurements of elemental concentrations. Also the density information obtained through the STIM spectra can also be used to normalise PIXE data for quantitative elemental determinations [21, 22].

Maps of the scanned sample regions were generated assigning the various detector signals to a digital $X-Y$ positional coordinate. The relative amount measured is represented by a colour gradient [23]. The size of the areas scanned matched the size of the thalli that was of the order of $150 \times 150 \mu \mathrm{m}$. Detailed images of specific features and point analyses along transects rendering concentration profiles were also produced. Previous to analysis the integrity of the sections were checked under the light microscope.

\section{Results}

Flavoparmelia caperata is a foliose lichen dorsiventrallyflattened against the substrate, and attached to the substrate by small root-like structures call rhizines. The thallus is stratified. The micrograph in Fig. 1 illustrates the typical cross-section of the thallus inspected by Nuclear Microprobe analysis. The microprobe scans were performed along the thallus layered structure. The upper and lower surfaces consist of a dense conglutinated layer of fungal filaments, upper and lower cortex. The central area corresponds to medulla region, which are less dense, consisting of relatively thick layer of spongy fungi hyphae. The algal layer is located in the upper portion of medulla, immediately beneath the upper cortex. Table 1 shows the elemental distribution in transversal cuts of young and old parts of $F$. Caperata thallus. The $156 \times 156 \mu \mathrm{m}$ scan 


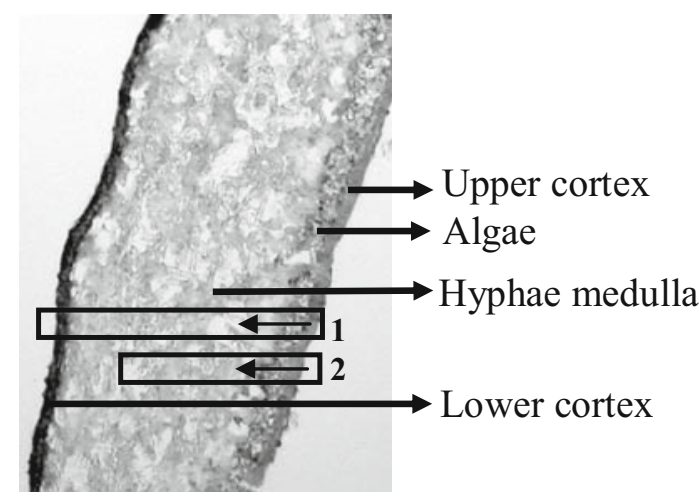

Fig. 1 Light microscope image $(10 \times$ magnification) Flavoparmelia caperata cross section. Structural layers are labelled. The rectangles indicate the zone and direction of the point analysis performed: $1-$ Zone scanned in young lichen thallus; 2-Zone scanned in old lichen thallus

covered all thallus area, as illustrated in Fig. 1. The $53 \times 53 \mu \mathrm{m}$ rows depict a detail of the above scanned area corresponding to the algae layer.

Main features were evidenced by the $\mathrm{P}, \mathrm{S}, \mathrm{Cl}, \mathrm{K}, \mathrm{Ca}$, and $\mathrm{Fe}$ distributions. In general elemental distributions correlate with the mass distribution, being the superior layer (upper cortex and algae layer), followed by the lower cortex that concentrates most of these elements. Non-metal elements like $\mathrm{S}, \mathrm{P}$, and $\mathrm{Cl}$ are more abundant in the upper layer. In young lichen parts $\mathrm{P}$ and $\mathrm{S}$ distribution clearly defines the algae layer while at the old lichen parts the distribution of these elements is more diffuse. Ca exhibits a somewhat granular distribution especially in the older thallus, it is abundant in the superior zone but also in some zones of medullar hypha. In the younger part of the thallus $\mathrm{Ca}$ appears more regularly distributed in the zone around the algae layer.

Iron is most abundant in algae, and shows a second peak of concentration in the lower cortex. The superior cortex presents the smallest element concentrations while the inferior cortex is rich in chlorine, phosphorous, potassium and iron. The medullar layer generally shows low element quantities except for some spots of high chlorine concentration, especially in younger thallus, and calcium concentration.

Figure 2 presents the elemental concentration profiles obtained by sequential point analysis performed along transversal transects of the young and old part of the lichen (see Fig. 1). Differences between the older and younger parts of the thallus can be seen in the distributions of $\mathrm{Ni}, \mathrm{Si}$ and Ti that are more abundant in the old parts of the thallus. $\mathrm{Ni}$ is only present in the old medulla, it appears dispersed, not concentrated in particles or crystallized structures. Si and $\mathrm{Ti}$ are present in the algae layer of both parts, but especially in some spots of the old medulla. Zn and Mn had a relatively uniform level across the thallus. Mn presented one point of high concentration in the young part of the thallus. $\mathrm{Cu}$ and $\mathrm{Al}$ were found in the algae layer of both lichen parts and showed an irregular distribution in the medulla. High $\mathrm{Cu}$ concentration spots were found in the medulla of old lichen parts.

Table 1 PIXE maps of elemental distribution in transversal cuts of peripheral and central parts of the thallus of Flavoparmelia caperata

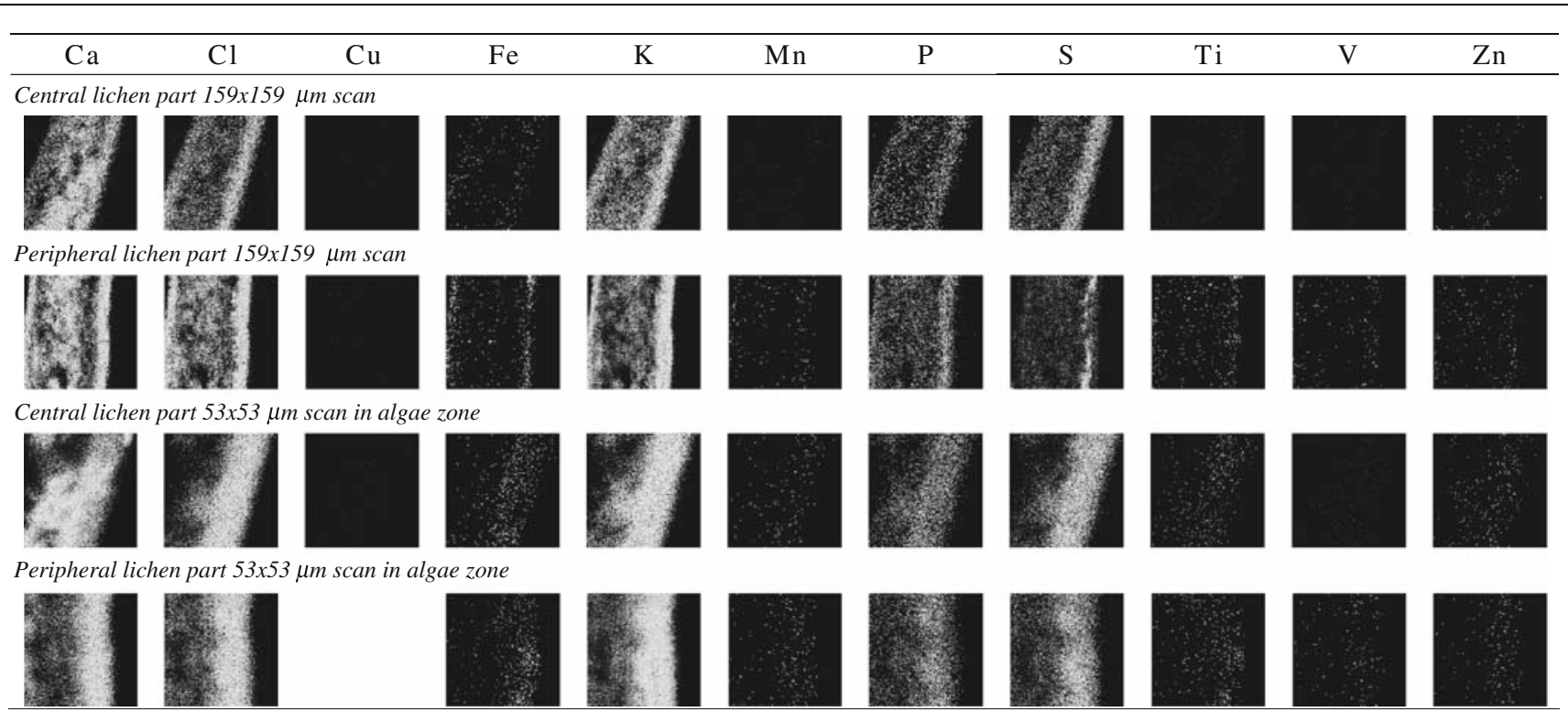

The relative amount is represented by the gradient from dark (minimum) to white (maximum).The thallus orientation corresponds to the Fig. 1 being the algae layer on the right side of the picture 
Fig. 2 Concentration values obtained in the point analysis transect performed on the central and peripheral Flavoparmelia caperata thallus parts (see Fig. 1). Empty circles refer to central lichen part; Filled squares refer to peripheral lichen part. Categories in the $X$ axis refer to spatial localization in the lichen: $U C$ upper cortex, $A$ algae layer, $M$ medullar hypha layer, $L C$ lower cortex

Table 2 shows correlation coefficients between the element concentration values shown in Fig. 2. Ca was the only element for which significant positive correlation was found between the distribution concentration in the young and old lichen parts. Al presents a significant but negative correlation meaning that where older part presents higher $\mathrm{Al}$ concentrations the younger part presents low. Comparing the patterns of element associations in each lichen part, it can be observed $\mathrm{K}$ associates with $\mathrm{S}$ and $\mathrm{Cl}$ in both parts. With this exception, elements combine differently in the different lichen parts.

\section{Discussion}

The data shows a significant degree of element partitioning in thalli of the foliose lichen F. caperata. Physiological elements like $\mathrm{K}, \mathrm{P}$ and $\mathrm{S}$ presented similar distribution in both young and old lichen parts. In contrast to the progressive decreasing of concentrations from the external layers described for Xanthoparmelia chlorochroa by [24], the elemental distributions observed suggest selective transport according to metabolic activity. The more pronounced pattern on younger lichens parts reinforces this idea. In this work the, algae layer of young and older lichen parts concentrated the majority of the elements, both those of physiological importance and metals such as $\mathrm{Fe}$ and $\mathrm{Cu}$. Although, microdistributions in exposed lichens reported are not consensual, the high levels of elemental concentrations in the algae layer may suggest lichen sensitivity to high environmental concentrations, namely sulphur.

On the other hand crustal and non metabolic elements like $\mathrm{Ni}, \mathrm{Si}$ and $\mathrm{Ti}$ presented different patterns of distribution in young and in older lichen parts. In younger lichen the second peak of concentrations is mainly localized in the lower cortex. A concentration rise in lower cortex of lichens exposed, to pollutants was reported $[12,13]$ suggesting a protective role of this structure. In the older parts of the lichen the localised high concentrations of $\mathrm{Ca}$ in the medulla may indicate the presence of calcium oxalate crystals as described by [24, 25]. In both young and older lichen parts particle entrapment in the hypha medullar area could not be observed.

The distribution data of the elements studied suggests that beside passive accumulation there is biological regulation of internal concentrations. Results indicate that

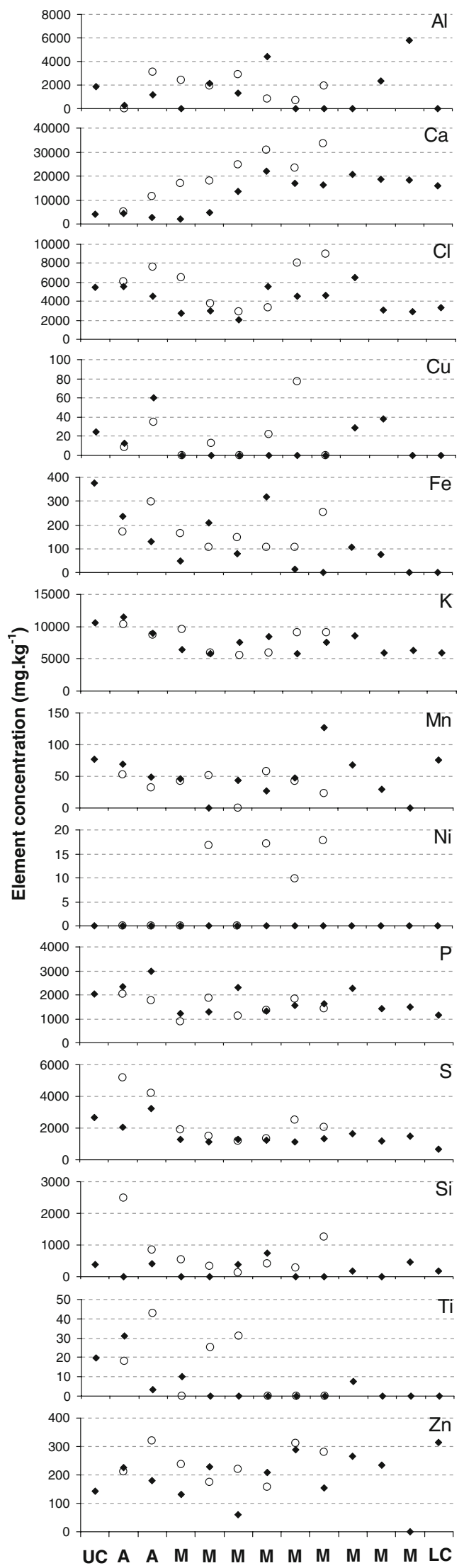




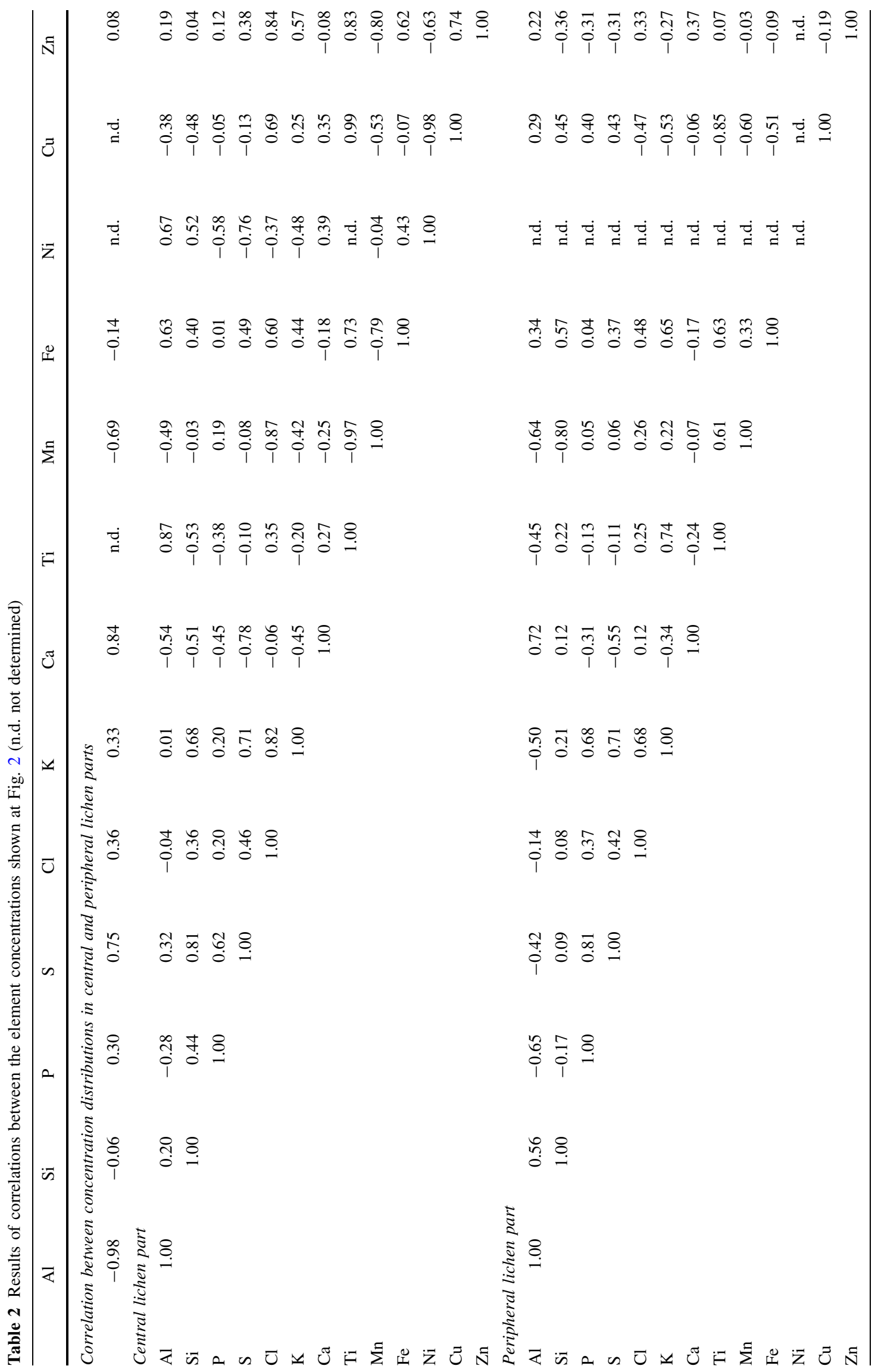


elements are not only entrapped but can be mobilized in the thallus suggesting an easy interchange with environment. This agrees with high and fast accumulation previously observed, maybe explained by high capacity of the lower cortex, and points to low remembrances times.

\section{Conclusions}

Considering thallus parts, element-specific internal translocation should be taken into account as one more factor affecting lichen "memory length". This observation suggests that tissue selection in monitoring should be dependent on the element of interest, and cannot be made into a generalized approach in survey setups: the choice depends on the element.

Acknowledgements A PhD grants from Fundacão para a Ciência e a Tecnologia and the European Social Fund support the work of the first author.

\section{References}

1. Loppi, S., Nelli, L., Ancora, S., Bargagli, R.: Bryologist 100, 251 (1997)

2. Bargagli, R., Mikhailova, I.: In: Nimis, P.L., Scheidegger, C., Wolseley, P.A. (eds.) Monitoring with Lichens-Monitoring Lichens, p. 65. Kluwer Academic Publishers, Dordrecht (2002)

3. Godinho, R.M., Verburg, T., Freitas, M.C., Wolterbeek, H.Th.: Environ. Pollut. 157, 102 (2009)

4. Nimis, P.L., Andreussi, S., Pittao, E.: Sci. Total Environ. 275, 43 (2001)

5. Reis, M.A., Alves, L.C., Freitas, M.C., Van Os, B., Wolterbeek, H.Th.: Sci. Total Environ. 232, 105 (1999)
6. Wolterbeek, H.T., Garty, J., Reis, M.A., Freitas, M.C.: In: Markert, B.A., Breure, A.M., Zechmeister, H.G. (eds.) Bioindicators \& Biomonitors, p. 377. Elsevier, Amsterdam (2003)

7. Godinho, R.M., Wolterbeek, H.Th., Verburg, T., Freitas, M.C.: Environ. Pollut. 151, 325 (2008)

8. Brown, D.H.: In: Munawar, M., Hänninen, M., Roy, O., Munawar, S., Kärenlampi, N., Brown, D.H. (eds.) Bioindicators of Environmental Health, p. 203. SPB Academic Publishing, Amsterdam (1995)

9. Hauck, M., Mulack, C., Paul, A.: Environ. Exp. Bot. 48, 107 (2002)

10. Garty, J., Theiss, H.B.: Bot. Acta 103, 311 (1989)

11. Mesjasz-Przybylowicz, J., Przybylowicz, W.J.: Nucl. Instr. Meth. B 189, 470 (2002)

12. Clark, B.M., Mangelson, N.F., Clair, L.L.S., Gardner, J.S., Cooper, L.S., Rees, L.B.: Nucl. Instr. Meth. B 150, 248 (1999)

13. Budka, D., Przybyłowicz, W.J., Mesjasz-Przybyłowicz, J., Sawicka-Kapusta, K.: Nucl. Instr. Meth. B 189, 499 (2002)

14. Ayrault, S., Clochiatti, R., Carrot, F., Daudin, L., Bennett, J.P.: Sci. Total Environ. 372, 717 (2007)

15. Ohnuki, T., Sakamoto, F., Kozai, N., Sakai, T., Kamiya, T., Satoh, T., Oikawa, M.: Nucl. Instr. Meth. B 210, 407 (2003)

16. Branquinho, C., Catarino, F., Brown, D.H., Pereira, M.J., Soares, A.: Sci. Total Environ. 232, 67 (1999)

17. Garty, J., Galun, M., Kessel, M.: New Phytol. 82, 159 (1979)

18. Sloof, J.E., Wolterbeek, B.Th.: J. Environ. Radioact. 16, 229 (1992)

19. Mrak, T., Simcic, J., Pelicon, P., Jeran, Z., Reis, M.A., Pinheiro, T.: Nucl. Instr. Meth. B 260, 245 (2007)

20. Godinho, R.M., Freitas, M.C., Wolterbeek, H.Th.: J. Atmos. Chem. 49, 355 (2004)

21. Alves, L.C., Breese, M.B.H., Alves, E., Paul, A., Da Silva, M.R., Da Silva, M.F., Soares, J.C.: Nucl. Instr. Meth. B 161-163, 334 (2000)

22. Veríssimo, A., Alves, L.C., Filipe, P., Silva, J.N., Silva, R., Ynsa, M.D., Gontier, E., Moretto, P.H., Pallon, J., Pinheiro, T.: Microsc. Res. Tech. 70, 302 (2007)

23. Grime, G.W., Dawson, M.: Nucl. Instr. Meth. B 104, 107 (1995)

24. Clark, B.M., St. Clair, L.L., Mangelson, N.F., Rees, L.B., Grant, P.G., Bench, G.S.: Am. J. Bot. 88, 1742 (2001)

25. Wadsten, T., Moberg, R.: Lichenologist 17, 239 (1985) 